\title{
STUDY OF WET CHEMICAL ETCHING OF BaSrTIO3 FERROELECTRIC THIN FILMS FOR INTELLIGENT ANTENNA APPLICATION
}

\author{
S. PAVY, C. BORDERON, S. BARON, R. RENOUD, H.W. GUNDEL \\ IETR, UMR 6164, University of Nantes, \\ 2 rue de la Houssiniere, Nantes, F-44300, France \\ E-mail: caroline.borderon@univ-nantes.fr
}

\begin{abstract}
Wet chemical etching of $\left(\mathrm{Ba}_{1-\mathrm{x}} \mathrm{Sr}_{\mathrm{x}}\right) \mathrm{TiO}_{3}$ (BST) thin films has been investigated. The etchant was prepared from buffered hydrofluoric acid (BHF) and nitric acid $\left(\mathrm{HNO}_{3}\right)$, BHF being the reactive agent while $\mathrm{HNO}_{3}$ acts as a catalyst. X-ray diffraction and energy dispersive X-ray spectrometry were performed in order to qualitatively and quantitatively follow the etching process. Scanning electron microscopy and a profilometer were used for determining the etching quality. The ferroelectric thin films were elaborated by a modified sol-gel process and by spin-coating on insulating (Si-wafers) or metal (stainless steel) substrates. Classic photolithography technique and a positive photo resist were used for the transfer of the patterns. Appropriate water dilution reduces the etching speed, thus allowing a better visual control of the process.
\end{abstract}

\section{INTRODUCTION}

Due to its high and tunable dielectric permittivity, $\left(\mathrm{Ba}_{1-\mathrm{x}} \mathrm{Sr}_{\mathrm{x}}\right) \mathrm{TiO}_{3}$ (BST) thin films appear to be one of the most studied candidates among ferroelectric materials for the development of intelligent microelectronic components such as microwave devices [1-4] and are more particularly proposed for the realization of reconfigurable telecommunication systems. The mobility requirement of today's smart phones and i-pad computers, together with the ever growing number of services (phone, internet, digital television, GPS, Bluetooth...) to be incorporated, comes along with the need of high level integration in order to reduce size, weight and energy consumption of those embarked devices. Innovative antenna topologies with tunable frequency characteristics play a major role in this development. The use of ferroelectrics may contribute to the material aspect of this task as the high-k property and the permittivity tunability make them suitable for device miniaturization and functionalization. Main inconvenient of ferroelectric materials are somewhat too high dielectric losses and, depending on the elaboration method, integration of the films as they may be subject to a high-temperature post-deposition crystallization process.

Miniaturized reception or emission antennas are conceived either in a metal-insulatormetal (MIM) or in a coplanar topology [5-7]. The resonance frequency and the antenna performance depend on the electrode geometry and the permittivity of the underlying substrate. Using substrates which are coated with electrically tunable dielectric materials such as ferroelectrics hence allow the design of reconfigurable antenna systems. While an increase of the substrate's effective permittivity by an superposed ferroelectric thin film reduces the antenna size, its relatively high dielectric losses lessen the antenna efficiency. Localized implementation of the ferroelectric in a strategic part of the antenna topology would allow to benefit from tunability without degrading the global antenna characteristics. Precise patterning by a simple means thus does not only present an advantage for integration of the material but also allows confining the ferroelectric and hence its dielectric properties to a particular area of the projected device topology. 
Whereas BST thin film elaboration and characterization techniques have widely been studied during the last decade, segmentation of this material is almost not reported. In the present work, we study wet chemical etching of BST ceramic thin films as a simple and low cost method which allows to develop tunable ferroelectric antennas. Optimization of the etching solution by combination of different acid components has been investigated and X-ray diffraction analysis has been used for a better understanding of the chemical reactions during the etching process. The etching rate has been controlled by dilution of the acids. Only few studies have already shown that buffered hydrofluoric acid (BHF) combined with an acid catalyst is an effective etching solution [8,9], the details of the ongoing chemical reactions, however, are not reported.

\section{ELABORATION OF THE BST THIN FILMS}

$\mathrm{Ba}_{0,80} \mathrm{Sr}_{0,20} \mathrm{TiO}_{3}$ (BST) thin films were realized by a modified sol-gel process based on the use of an alkoxide precursor [10]. Barium acetate $\mathrm{Ba}\left(\mathrm{OOCCH}_{3}\right)_{2}$ is mixed with strontium acetate $\mathrm{Sr}\left(\mathrm{OOCCH}_{3}\right)_{2}$ in suitable proportions in order to obtain a $\mathrm{Ba} / \mathrm{Sr}$ ratio of $80 / 20$. The obtained powder is dissolved in distilled water and anhydride acetic acid and the solution is heated at $100^{\circ} \mathrm{C}$ until complete dissolution and then cooled down to room temperature before addition of titanium n-propoxide $\mathrm{Ti}\left(\mathrm{C}_{3} \mathrm{H}_{7} \mathrm{O}\right)_{4}$. Ethylene glycol $\mathrm{HO}-\mathrm{CH}_{2}-\mathrm{CH}_{2}-\mathrm{OH}$ is added in order to retain the mobility of the atoms and significantly reduces cracking of the film [11]. Moreover, addition of ethylene glycol stabilizes the solution and prevents from precipitation [12]. In order to influence nucleation at the interface and cause layer by layer grain growth, the solution is diluted and the viscosity is adjusted to 2,1 mPa.s. Before deposition on the substrate, the solutions are filtered with a $0.2 \mu \mathrm{m}$ PTFE filter. Spin-coating is done at 4000 rpm during 20 seconds and the samples are annealed during $15 \mathrm{~min}$ in a pre-heated open air furnace at $750^{\circ} \mathrm{C}$. Direct annealing (without a prior drying stage) is employed in order to obtain a larger average grain size due to a nucleation and a crystallization at the layer interface (heterogeneous nucleation) [13] which is supposed to result in an increased permittivity of the material $[14,15]$. The BST, used for this study, has a relative permittivity of 450 and dielectric losses close of 0.01 [16]. Multiple spin-coating is used when thicker BST layers are desired. A dense and homogeneous polycrystalline BST film is obtained, the cross-section and surface micrographs of which are shown in Fig. 1.

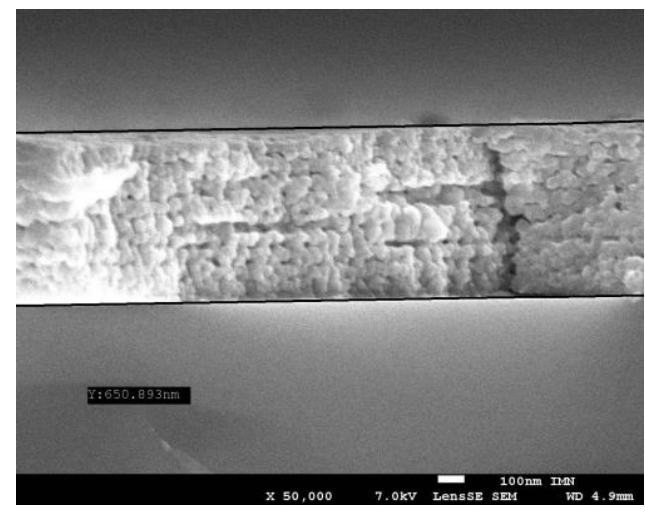

(a)

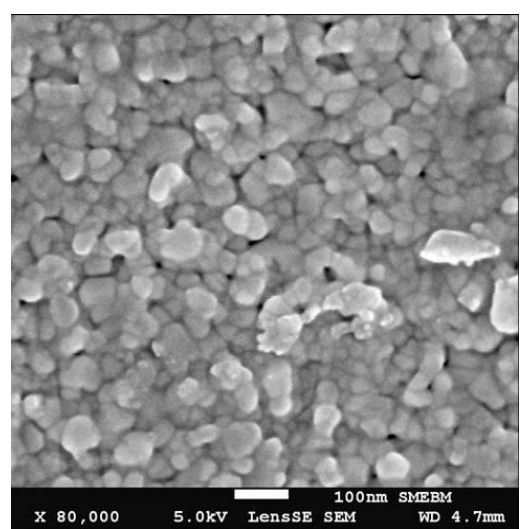

(b)

Figure 1: SEM cross-section micrograph (a) and surface micrograph (b) of a 10 layer $\mathrm{Ba}_{0,80} \mathrm{Sr}_{0,20} \mathrm{TiO}_{3}$ film deposited on Si substrate

For the present study, two different substrates were used: stainless steel (AISI 304, composition: $\mathrm{Ni}_{0.08} \mathrm{Cr}_{0.18} \mathrm{Fe}_{0.74)}$ and silicon wafers $(\mathrm{Si})$. The metal substrate allows a more easy reading of the X-ray diffraction diagrams but it is a polycrystalline substrate with a 
similar appearance than the thin film on SEM image, the Si-wafers allow a better observation of the sample cross-section as neatly cleaving is possible (silicon wafers $(\mathrm{Si})$ n-type with a crystal orientation $\langle 100>$ ). The overall BST film thickness is typically $650 \mathrm{~nm}$ and $1 \mu \mathrm{m}$ for a deposition of ten layers on Si and on stainless steel, respectively. The BST grain size is approximately $50 \mathrm{~nm}$. Classic photolithography technique using a positive photo resist (Shipley S1818 G2) has been employed for the transfer of the mask pattern to the BST thin films.

\section{ETCHING AGENT AND CHEMICAL EQUATION}

To begin with, several pure acids have been tested with respect to their etching facility. BST thin films deposited on stainless steel substrates were subjected during 30 minutes to buffered hydrofluoric acid (commercial BHF from Sigma Aldrich), $\mathrm{HNO}_{3} 65 \%, \mathrm{H}_{2} \mathrm{SO}_{4} 50 \%$ and $\mathrm{H}_{3} \mathrm{PO}_{4} 85 \%$. Except for BHF, where the BST was clearly attacked, no etching action could be observed. The X-ray diagrams of the BST thin film before and after 30 minutes etching with BHF are shown in Fig. 2. After etching, only a thin and mat veil can be seen on the substrate's surface. The characteristic BST lines in the X-ray diagram being disappeared, the thin film seems to be etched completely. The new lines in the diagram are supposed to correspond to etching products as $\mathrm{HF}$ reacts with $\mathrm{BST}$ resulting in $\mathrm{BaF}_{2}, \mathrm{SrF}_{2}$ and $\mathrm{TiF}_{4(\mathrm{~s})}$ [9]:

$$
\left(\mathrm{Ba}_{1-x} \mathrm{Sr}_{x}\right) \mathrm{TiO}_{3(s)}+\mathrm{HF}_{(a q)} \rightarrow(1-x) \mathrm{BaF}_{2(s)}+x \mathrm{SrF}_{2(s)}+\mathrm{TiF}_{4(s)}+3 \mathrm{H}_{2} \mathrm{O}
$$

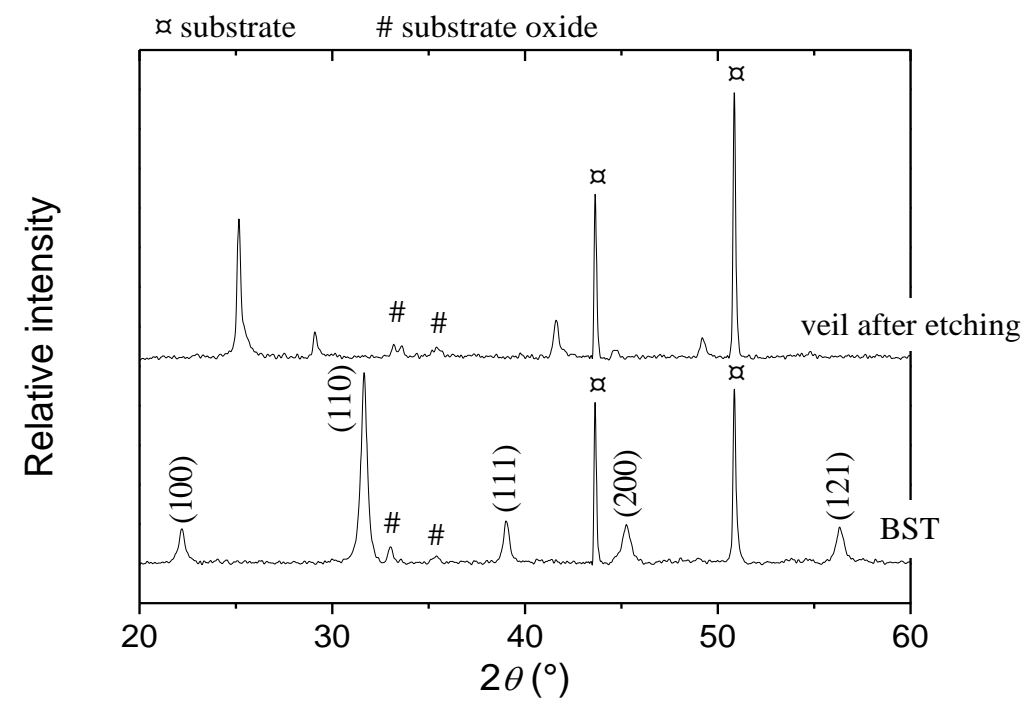

Figure 2: X-ray diagram of BST and the substrate after etching with BHF

In order to verify the existence of the etching products, the respective X-ray diagrams have been calculated. As $\mathrm{TiF}_{4}$ is completely miscible in water, and even more in an acid solution, we suppose that it would have been evacuated when rinsing the substrates. Detection by titration was impossible due to the presence of fluoride ions in the etching solution, that prevent from the use of glass electrodes, traditionally allowing following a reaction by conductimetry, pHmetry or potentiometric analysis.

The ICSD calculated $\mathrm{BaF}_{2}$ and $\mathrm{SrF}_{2} \mathrm{X}$-ray diagrams are shown in Fig. 3 together with the diagram of the observed mat veil. Intermediate peak positions for the mat veil let us suppose that the $\mathrm{Ba} / \mathrm{Sr}$ ratio may be maintained during the etching reaction, thus resulting in $\left(B a_{1-x} S r_{x}\right) F_{2(s)}$. 


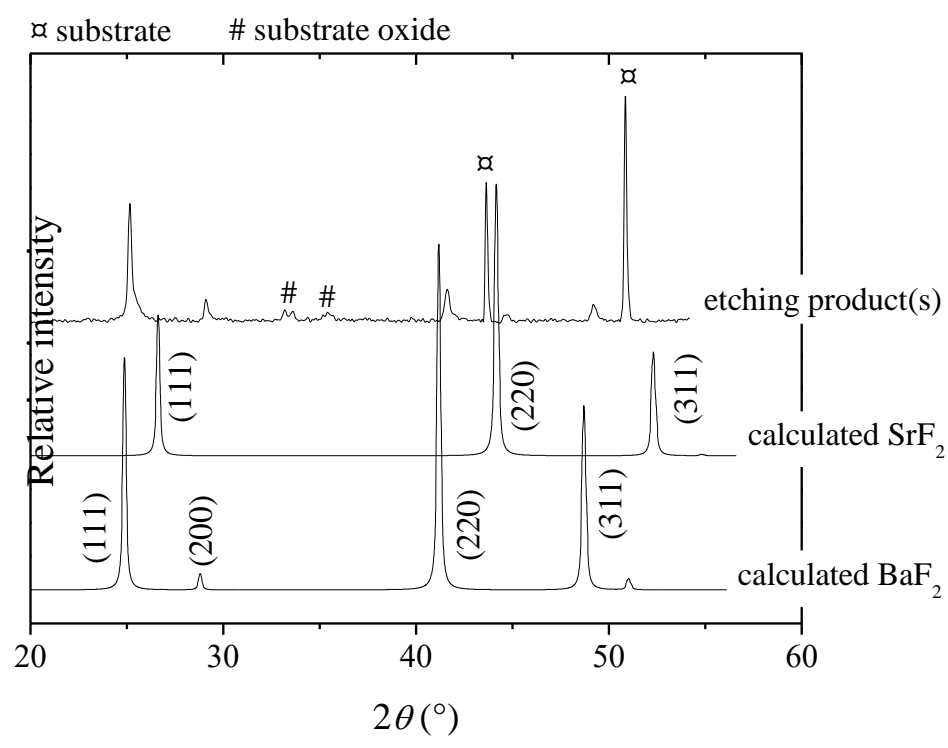

Figure 3: $\mathrm{X}$-ray diagrams of the etching product(s) and of calculated $\mathrm{BaF}_{2}$ and $\mathrm{SrF}_{2}$

Simulation of the $\mathrm{Ba}_{0,8} \mathrm{Sr}_{0,2} \mathrm{~F}_{2} \mathrm{X}$-ray diagram with the Powerdcell software reveals a very good match of the line positions with those of the etch product as it is shown in Fig. 4.

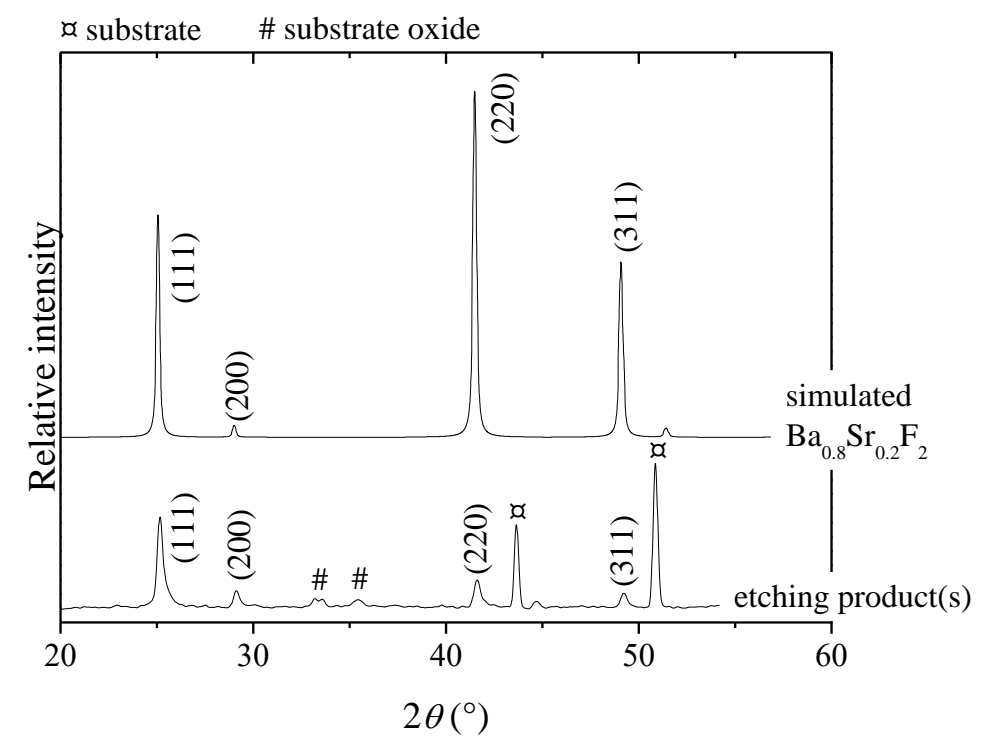

Figure 4: X-ray diagrams of the etching product(s) and of simulated $\mathrm{Ba}_{0.8} \mathrm{Sr}_{0.2} \mathrm{~F}_{2}$

Supplementary EDX analysis confirm that the $\mathrm{Ba} / \mathrm{Sr}$ ratio of the original BST thin film is nearly kept in the product which composes the thin and mat veil and that all $\mathrm{Ti}$ atoms have been removed. BST etching with BHF hence is governed by the chemical reaction:

$$
\left(\mathrm{Ba}_{1-x} \mathrm{Sr}_{x}\right) \mathrm{TiO}_{3(s)}+6 \mathrm{HF}_{(a q)} \rightarrow\left(\mathrm{Ba}_{1-x} \mathrm{Sr}_{x}\right) \mathrm{F}_{2(s)}+\mathrm{TiF}_{4(s)}+3 \mathrm{H}_{2} \mathrm{O}
$$




\section{CATALYSIS AND OPTIMIZATION OF THE ETCHING SOLUTION}

While the results show that BHF is an efficient BST etching agent, when being used pure, it appears not to be satisfying with respect to the required etching precision. Moreover, BHF is known to attack $\mathrm{SiO}_{2}$, which might be inconvenient when using $\mathrm{Si}$ substrates. In order to selectively etch the BST thin film and to control the etching rate, catalysis of the HF agent was proposed [8]. HF is a weak acid and hence is partially disassociated in solution [17]:

$$
\mathrm{HF}+\mathrm{H}_{2} \mathrm{O} \longleftrightarrow \mathrm{F}^{-}+\mathrm{H}_{3} \mathrm{O}^{+} \quad \mathrm{pKa}=3,20
$$

Supposing that BST will be etched in a similar way as silicon dioxide, the etching rate should increase linearly with the concentration of $\mathrm{HF}$ and $\mathrm{HF}_{2}{ }^{-}$[18], while being independent from the $\mathrm{F}^{-}$-ion concentration. Thus, a strong acid like $\mathrm{HNO}_{3}\left(p K_{a}=-1,37\right)$ would influence the equilibrium such as to favor the formation of HF molecules and catalyze the etching reaction. Moreover, in order to keep the HF concentration constant and hence to stabilize the etching rate, $\mathrm{HF}$ can be buffered with $\mathrm{NH}_{4} \mathrm{~F}$ which disassociates and liberates fluoride ions. As the solution is strongly acidified by $\mathrm{HNO}_{3}(65 \%$ pure), the $\mathrm{HF}$ generation will be maintained which is a major advantage for the use of a BHF solution instead of a HF acid.

Contrary to $\mathrm{TiF}_{4}$, the observed $\left(\mathrm{Ba}_{0,8} \mathrm{Sr}_{0,2}\right) \mathrm{F}_{2}$ etching product is not very soluble in the etching solution, and hence remains on the substrate when the buffered hydrofluoric acid $(\mathrm{pH}$ $=3$ ) is used alone. As the solubility of any species is increased when lowering the $\mathrm{pH}$ value, addition of $\mathrm{HNO}_{3}$ allows to attain a value $\mathrm{pH}<1$ which helps dissolving $\left(\mathrm{Ba}_{0,8} \mathrm{Sr}_{0,2}\right) \mathrm{F}_{2}$. The mat and thin veil, initially visible at the sample surface after etching, was not anymore observed.

The nitric acid being identified as an effective catalysis agent, its proportion in the etching solution has to be optimized. Classic photolithography technique has been used in order to pattern a $650 \mathrm{~nm}$ thick BST film deposited on a silicon substrate, also allowing to compare the etching quality and resolution of each sample by scanning electron microscopy (SEM). Six different $\mathrm{BHF} / \mathrm{HNO}_{3}$ volume ratios from 100/0 to $50 / 50$ have been tested. An etching duration of 20 seconds was arbitrarily fixed.

When the using a solution with 20 percent of nitric acid or less, the BST film could not be completely etched. At the same time, the BST patterns, supposed to be protected by the photo resist, were also attacked at the material's grain boundaries. The results are illustrated in Fig. 5. The surface roughness is increased in this case and is in the range of the grain size (approximately $50 \mathrm{~nm}$ ). Moreover, the silicon oxide at the wafer surface was etched, too, which indicates that the solution does not allow selective etching (see Fig. 6). When the etching solution contains $30 \%$ in volume of $\mathrm{HNO}_{3}$ pure at $65 \%$ and $70 \%$ of BHF, the BST patterns are quite well defined (Fig. 7) and the silicon substrate $\mathrm{SiO}_{2}$ is not anymore attacked. In addition, the BST, which is protected by the resin, is not attacked and the surface roughness is unchanged. At $40 \% \mathrm{HNO}_{3}$ or at even higher content of nitric acid, the BST thin films are over etched (Fig. 8). 


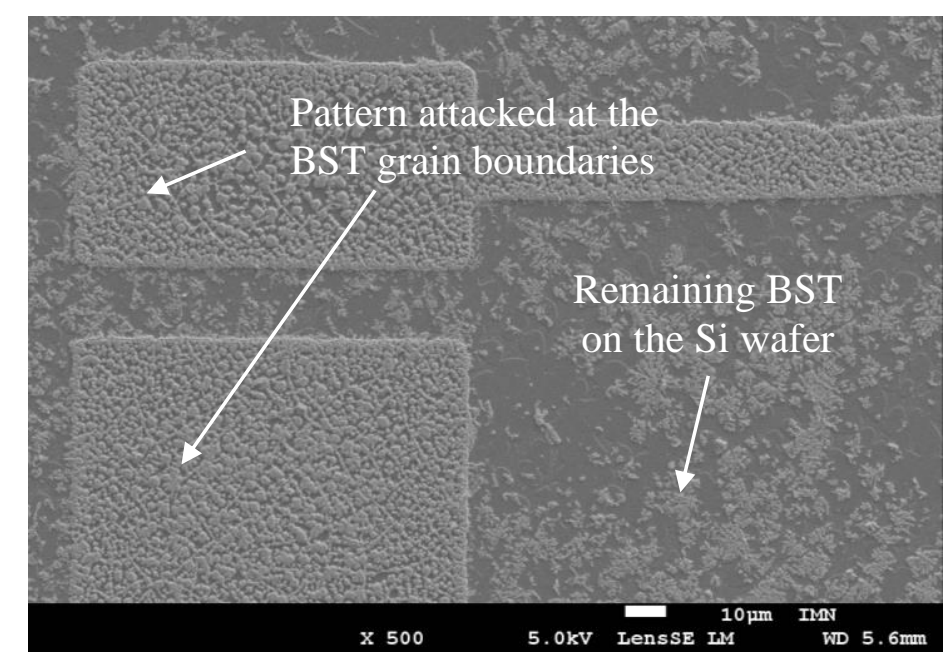

Figure 5: SEM surface micrograph of BST deposited on Si and etched during 20 seconds in a 90/10 $\mathrm{BHF} / \mathrm{HNO}_{3}$ solution

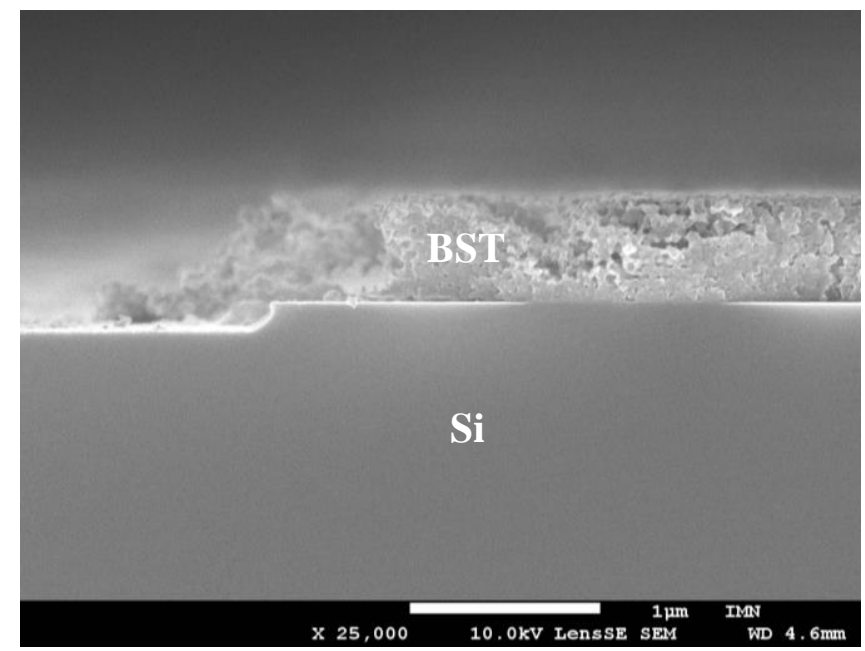

Figure 6: SEM cross-section micrograph of the BST layer deposited on Si and etched during 20 seconds in a $80 / 20 \mathrm{BHF} / \mathrm{HNO}_{3}$ solution

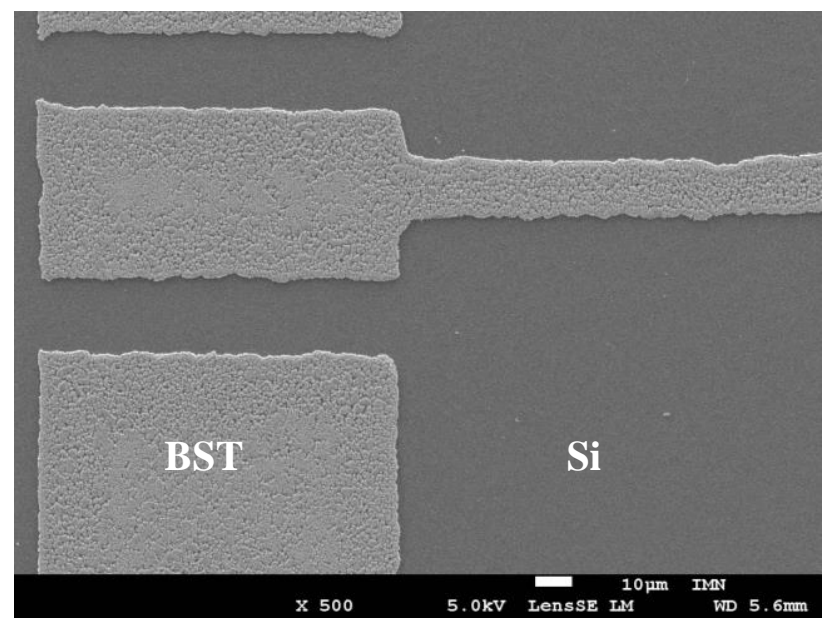

Figure 7: SEM surface micrograph of BST deposited on Si and etched during 20 seconds in 70/30 BHF/ $/ \mathrm{HNO}_{3}$ solution 


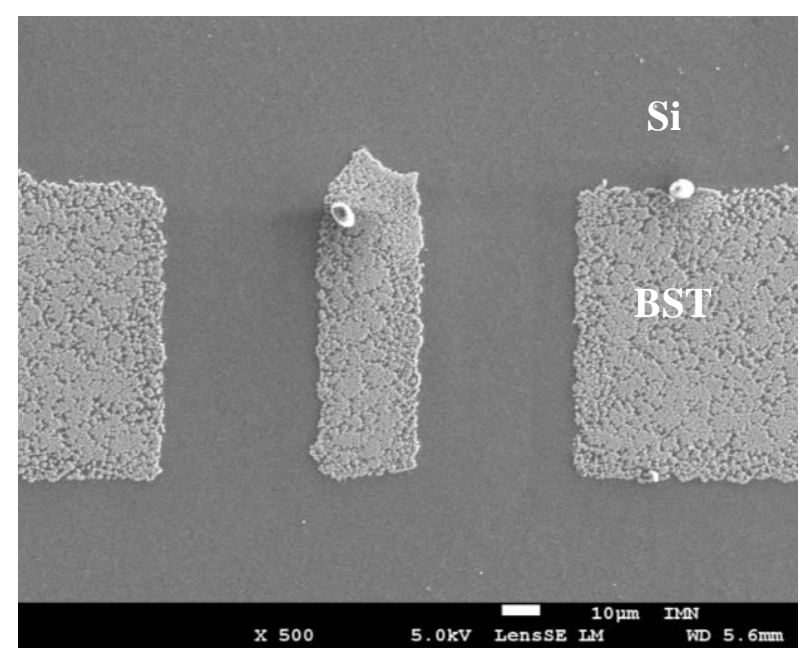

(a)

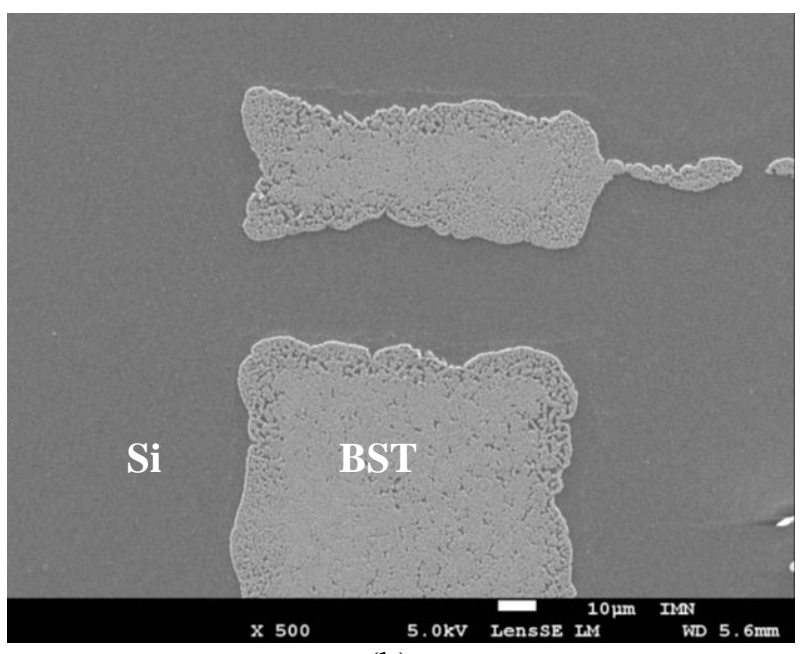

(b)

Figure 8: SEM surface micrograph of BST deposited on $\mathrm{Si}$ and etched during 20 seconds in $60 / 40 \mathrm{BHF} / \mathrm{HNO}_{3}$ solution (a) and 50/50 $\mathrm{BHF} / \mathrm{HNO}_{3}$ solution (b)

After having defined the composition between etchant and catalyser, dilution in distilled water of the $70 / 30 \mathrm{BHF} / \mathrm{HNO}_{3}$ solution has been studied in order to slow down the etching reaction. This allows a visual control of the etching progress and improvement of the etching resolution. Several solution concentrations from $100 \%$ to $25 \%$ were tested. The etching process was stopped once the patterns appear to be completely revealed, however not before 20 seconds which is estimated to be the minimum duration for correctly controlling. The etching accuracy was determined with a profilometer (Veeco Dektak 32) by comparing the width of the photoresist pattern with the corresponding width of the BST after etching. The results for the different solution concentrations are shown in Table 1. Solution concentrations above $50 \%$ will not be considered since etching is too fast for being reasonably controlled. For all other concentrations, an etching accuracy between $0,84 \mu \mathrm{m}$ and $2 \mu \mathrm{m}$ was obtained which is a rather satisfying result for wet chemical etching of a ceramic complex oxide layer of $600 \mathrm{~nm}$ thickness. From the practical point of view, a solution concentration of $25 \%$ and an etching duration of 45 seconds is convenient. The results obtained under these conditions are illustrated in Fig. 9, also showing the isotropic character of the wet etching process, which naturally leads to a lateral attack of the BST layer. This isotropic etching was obtained for all solutions when there was not an overetching.

Table 1: Etching time and accuracy for different dilution of the $70 / 30 \mathrm{BHF} / \mathrm{HNO}_{3}$ etching solution

\begin{tabular}{|c|c|c|c|c|}
\hline $\begin{array}{c}\text { Solution } \\
\text { concentration }\end{array}$ & $\begin{array}{c}\text { Etching } \\
\text { time }\end{array}$ & $\begin{array}{c}\text { Photoresist } \\
\text { line width }\end{array}$ & $\begin{array}{c}\text { BST line } \\
\text { width }\end{array}$ & $\begin{array}{c}\text { Etching } \\
\text { accuracy }\end{array}$ \\
\hline $100 \%$ & 20 seconds & $105 \mu \mathrm{m}$ & overetching & $/$ \\
\hline $91,7 \%$ & 20 seconds & $105 \mu \mathrm{m}$ & overetching & $/$ \\
\hline $83,3 \%$ & 20 seconds & $106 \mu \mathrm{m}$ & overetching & $/$ \\
\hline $75,0 \%$ & 20 seconds & $105 \mu \mathrm{m}$ & overetching & $/$ \\
\hline $66,7 \%$ & 20 seconds & $105 \mu \mathrm{m}$ & $102,33 \mu \mathrm{m}$ & $1,34 \mu \mathrm{m}$ \\
\hline $58,3 \%$ & 20 seconds & $105 \mu \mathrm{m}$ & $102,33 \mu \mathrm{m}$ & $1,34 \mu \mathrm{m}$ \\
\hline $50,0 \%$ & 20 seconds & $105 \mu \mathrm{m}$ & $103,33 \mu \mathrm{m}$ & $0,84 \mu \mathrm{m}$ \\
\hline $41,7 \%$ & 30 seconds & $105 \mu \mathrm{m}$ & $101 \mu \mathrm{m}$ & $2 \mu \mathrm{m}$ \\
\hline $33,3 \%$ & 35 seconds & $107 \mu \mathrm{m}$ & $103 \mu \mathrm{m}$ & $2 \mu \mathrm{m}$ \\
\hline $25,0 \%$ & 45 seconds & $107 \mu \mathrm{m}$ & $105 \mu \mathrm{m}$ & $1 \mu \mathrm{m}$ \\
\hline
\end{tabular}




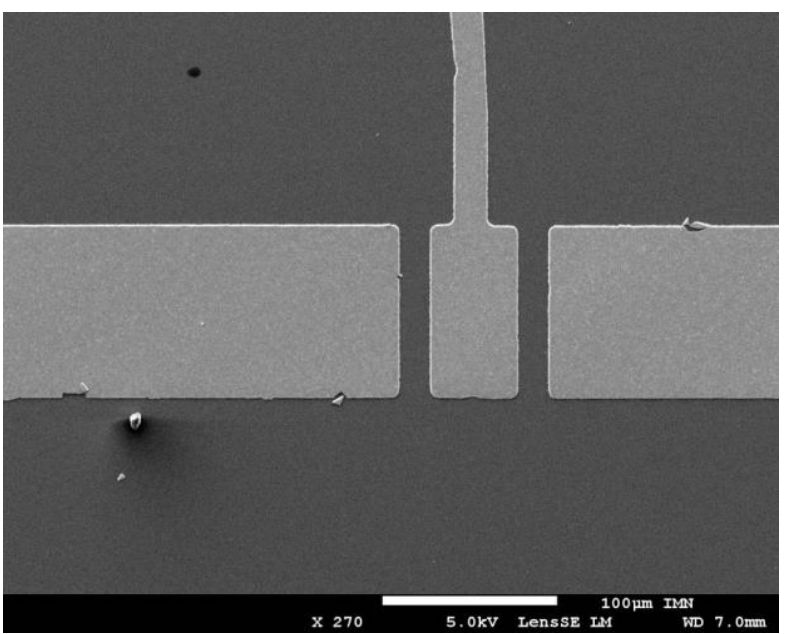

(a)

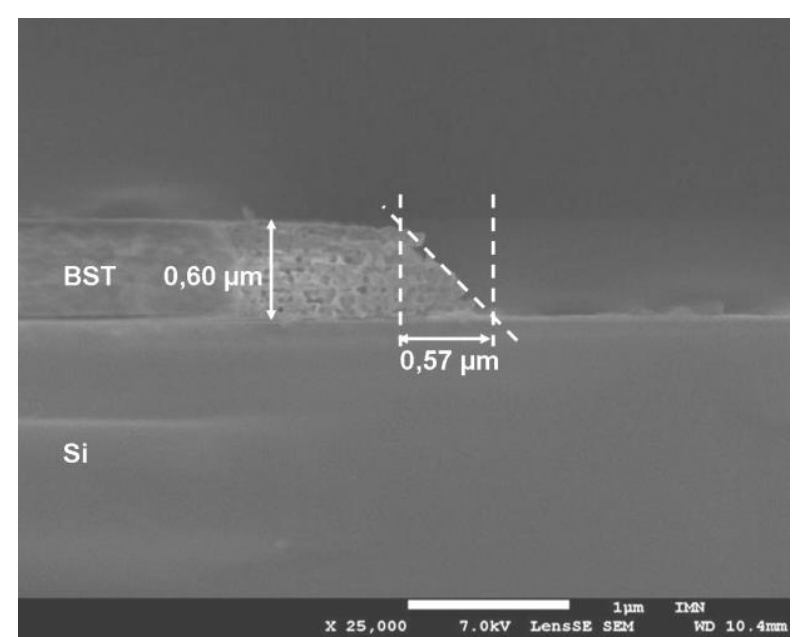

(b)

Figure 9: SEM surface (a) and cross-section (b) micrograph of a $600 \mathrm{~nm}$ thick BST layer etched with a $25 \%$ solution of $70 / 30 \mathrm{BHF} / \mathrm{HNO}_{3}$ during 45 seconds.

\section{CONCLUSIONS}

BST thin films elaborated by chemical solution deposition were etched with a commercial buffered hydrofluoric acid BHF (65\% pure) catalysed with nitric acid $\mathrm{HNO}_{3}$. A volume ratio of $70 / 30$ for the $\mathrm{BHF} / \mathrm{HNO}_{3}$ solution was found to be a selective etching agent for the BST layers. While X-Ray diffraction analysis indicates the chemical reaction of the etching process

$$
\left(\mathrm{Ba}_{1-x} \mathrm{Sr}_{x}\right) \mathrm{TiO}_{3(s)}+6 \mathrm{HF}_{(a q)} \rightarrow\left(\mathrm{Ba}_{1-x} \mathrm{Sr}_{x}\right) \mathrm{F}_{2(s)}+\mathrm{TiF}_{4(s)}+3 \mathrm{H}_{2} \mathrm{O},
$$

the etching solution had to be diluted in order to achieve satisfying resolution and for a convenient control of the etching process duration. Well-defined structures of micrometric dimension ( $15 \mu \mathrm{m}$ in our study) were obtained with a lateral resolution of approximately $1 \mu \mathrm{m}$ in the case of a $600 \mathrm{~nm}$ thick BST layer. This is perfectly adequate for patterning the functional ferroelectric material for integration into tunable antenna topologies. Even smaller patterns could be obtained with the same process parameters.

\section{REFERENCES}

[1] A. Vorobiev, P. Rundqvist, K. Khamchane, and S. Gevorgian, Microwave loss mechanisms in Ba0.25Sr0.75TiO3 thin film varactors, J. Appl. Phys., 96(8), 4642-4649 2004 [2] A. Outzourhit, J. U. Trefny, T. Kito, B. Yarar, A. Naziripour, and A. M. Hermann, Fabrication and characterization of Bal-xSr1-xTiO3 tunable thin film capacitors, Thin Solid Films, 259, 218-224, 1995

[3] G. Subramanyam, F. W. Van Keuls, F. A. Miranda, R. R. Romanofsky, and J. D. Warner, Designand development of ferroelectric tunable HTS microstripfilters for Ku- and $\mathrm{K}$ band applications, Mater. Chem. Phys., 79(2-3), 147-150, 2003

[4] J. Xu,W. Menesklou, and E. Ivers-Tiffee, Processing and properties of BST thin films for tunable microwave devices, J. Europ. Ceram. Soc. 24(6), 1735-1739, 2004

[5] H. Jiang, M. Patterson, C. Zhang, and G. Subramanyam, Frequency tunable Microstrip patch antenna using ferroelectric thin film varactor, Aerospace \& Electronics Conference (NAECON), Proceedings of the IEEE National, 248 - 250, 2009

[6] H. Jiang, M. Patterson, D. Brown, Z. Chenhao; P. KuanChang; G. Subramanyam,; D. Kuhl, K. Leedy, C. Cerny, Miniaturized and Reconfigurable CPW Square-Ring Slot Antenna Loaded With Ferroelectric BST Thin Film Varactors, IEEE Transactions on antennas and propagation, 60, no. 7, 3111-3119, 2012 
[7] Seyed Mohammad Saeed Majedi and Amir Reza Attari, A Compact MIM Zeroth Order Resonator Antenna, 5th International Symposium on Telecommunications, 310-311, 2010

[8] R.T. Zhang, Wet chemical etching method for BST thin films annealed at high temperature, Applied Surface Science, 254, 6697-6700, 2008

[9] R.T. Zhang, Wet chemical etching process of BST thin films for pyroelectric infrared detectors, Ferroelectrics, 410, 137-144, 2011

[10] C. Borderon, D. Averty, R. Seveno, H.W. Gundel, Preparation and characterization of barium strontium titanate thin films by chemical solution deposition, Ferroelectrics, 362, 17 (2008)

[11] A. Tombak, J. P. Maria, F. T. Ayguavives, J. Zin, G. T. Stauf, A. I. Kingon, and A. Mortazawi, Voltage-Controlled RF filters employing thin film Barium-Strontium-Titanate tunable capacitors. IEEE Trans. Microwave Theory Tech. 51(2), 462-466 (2003).

[12] M, Guilloux-Viry, J. R. Duclere, A. Rousseau, A. Perrin, D. Fasquelle, J. C. Carru, E. Cattan, C. Soyer, and D. Remiens, Dielectric characterization in a broad frequency and temperature range of SrBi2Nb2O9 thin films grown on Pt electrodes. J. Appl. Phys. 97, 114102/1-1014102/7 (2005).

[13] R.W. Schwartz, T. Schneller, and R. Waser, Chemical solution deposition of electronic oxide films, Comptes Rendus Chimie 7 (5), 433-461 (2004).

[14] A. Vorobiev, P. Rundqvist, K. Khamchane, and S. Gevorgian, Microwave loss mechanisms in Ba0.25Sr0.75TiO3 thin film varactors. J. Appl. Phys. 96(8): 4642-4649 (2004).

[15] A. Outzourhit, J. U. Trefny, T. Kito, B. Yarar, A. Naziripour, and A. M. Hermann, Fabrication and characterization of $\mathrm{Ba} 1-\mathrm{xSr} 1-\mathrm{xTiO} 3$ tunable thin film capacitors. Thin Solid Films 259, 218-224 (1995).

[16] K. Nadaud, C. Borderon, S. Pavy and H.W. Gundel, 2013 IEEE International Symposium on the Applications of Ferroelectric and Workshop on the Piezoresponse Force Microscopy (ISAF/PFM), At Prague, DOI: 10.1109 (2013).

[17] H. Kikyuama, N.Miki, K. Saka, J. Takano, I. Kawanabe, M. Miyashita, T. Ohmi, Principles of wet chemical processing in ULSI microfabrication, IEEE Trans. Semicond. Manufac., vol. 4, no. 1, 26-35, (1991)

[18] R. Kirt, Etch rates for micromachining processing, Journal of microelectromechanical systems, vol. 5, no. 4, (1996) 